\title{
Educación a distancia vía videoconferencia
}

Elena Mascheroni y Víctor Paulós

\section{RESUMEN}

La necesidad de extender cursos y carreras de nivel terciario al interior del país es una realidad inobjetable y advertida por todos. No obstante, pocos han sido los movimientos educativos tendientes a abordar esta problemática. La centralización de las actividades educativas terciarias en Montevideo hace que el interior del país esté vacío, en buena parte, de profesionales para dicho nivel. Esta innovación intenta aportar algunos elementos básicos a través de la implementación del dictado de un curso regular de

"Educación a distancia vía videoconferencia", colaborando en eliminar las barreras anteriormente expuestas y fomentando el abordaje y profundización de esta temática tan trascendente para la mitad de la población del país y para el país todo.

\section{OBJETIVOS DE LA INNOVACIÓN}

* Validar la tecnología de videoconferencia como medio educativo, con el fin de extender la enseñanza terciaria desde Montevideo hacia el interior del país logrando involucrar a los gobiernos nacional y departamentales como agentes "impulsores de desarrollo".

* Realizar la primera experiencia en la ciudad de Colonia del Sacramento con un "Programa de Desarrollo Gerencial " (PDG), en el período agosto-diciembre de 1996.

\section{MARCO TEÓRICO}

En estos días es posible apreciar en periódicos de los Estados Unidos, Canadá, la CEI y particularmente en el Reino Unido, entre otros países, una diversidad de ofertas de cursos universitarios a distancia. Algunas de estas experiencias han sido divulgadas y evaluadas; a modo de ejemplo, presentaremos información sobre una de ellas para fortalecer el referente teórico de nuestro trabajo.

Entre las investigaciones realizadas en la Universidad de Boston, J ohn Storck y Lee Sproull, en su trabajo "Through a glass Darkly - What Do People Learn in Videoconferences?" (Human Communication Research, Vol 22, No.2, Diciembre 1995), relatan su experiencia de investigación en educación a distancia a través de esta tecnología y su metodología.

La investigación se desarrolló en la Escuela de Ingeniería de una Universidad que ofrece cursos a nivel de maestría, a través de videoconferencia interactiva. Cada curso reúne aproximadamente de 20 a 30 estudiantes; algunos de ellos asisten a clase en el campus principal y otros atienden los cursos en sitios remotos. Los sitios están conectados entre sí a través de tecnología de video, creando una "clase compartida". Utilizando líneas de comunicación digital de 128 kbps y equipamiento de videocomprensión, cada salón puede elegir cuál sitio desplegar en la parte izquierda del monitor. La parte derecha del monitor generalmente es usada para presentar documentos o bien imágenes emitidas desde el sitio emisor. Todas las imágenes son en color y la comunicación de audio y video es en todos los sentidos; la sincronización de voz e imágenes no es total, produciéndose un "retardo" de 0.7 segundos en el audio.

La investigación arrojó como resultado relevante que la población de sitios remotos había incorporado conocimientos de igual grado, e inclusive mayores que la del sitio presencial. Referente a la percepción de los participantes, destaca que las impresiones que reciben los estudiantes de sitios remotos son diferentes con respecto al docente, dada la pérdida de significados en las expresiones del rostro, posturas y actitudes que manifiesta el lenguaje corporal.

Las investigaciones realizadas en la Universidad de Indiana ("Distance Learning: A Guide to System Planning and Implementation)" en 1996 fueron de suma utilidad por las consideraciones pertinentes al cuerpo docente. Sintetizamos las puntualizaciones que consideramos más relevantes en dicho estudio.

"La preparación de los instructores para enseñar en la modalidad de videoconferencia interactiva es fundamental y también su comprensión de las diferencias con la modalidad de enseñanza cara a cara; de esta forma, se anticiparán y evitarán las principales dificultades". Se deben tener en cuenta las siguientes consideraciones: 
* Alumnos y profesores pueden producir distracciones en forma inadvertida o consciente, diciendo o haciendo cosas que los micrófonos y cámaras registren. Todos nec esitarán ajustarse a esta realidad, por lo que las reglas para la comunicación ayudarán.

* Los profesores deben utilizar diversos métodos para asegurar y estimular la interacción, incluyendo la recolección de los currículos de los estudiantes, llamándolos por su nombre, compartiendo experiencias, estimulándolos a que lideren las discusiones, visitando los sitios remotos y ocasionalmente reuniendo a todos los estudiantes en un sitio.

\section{DESCRIPCIÓN DE LA EXPERIENCIA}

Nuestra idea fue ofrecer productos educativos lo suficientemente probados en la Universidad ORT Uruguay y con docentes con amplia experiencia en el dictado de los mismos. La selección de los módulos que forman parte de nuestro "Programa de Desarrollo Gerencial" (PDG) se basó en la percepción de necesidades de la zona, como así también en temas que resultaran atractivos para el perfil de los participantes (gerentes, ejecutivos). Los seminarios refieren a los siguientes temas: Gestión de Recursos Humanos, Marketing y Dirección Estratégica.

\section{¿CÓMO RECLUTAMOS A LOS ESTUDIANTES?}

Dadas las características del programa, efectuamos una selección previa de posibles interesados teniendo en cuenta la temática de los módulos seleccionados. Enfocamos la propuesta dirigiéndola a empresas de la zona, contactando dentro de dichas organizaciones a la persona con capacidad de decisión para integrarse por sí misma en esta experiencia, y/o poder designar funcionarios a su cargo como participantes. Por otra parte, buscamos "líderes" con amplio reconocimiento institucional, de forma que sus colegas - de otras organizaciones - sintieran la necesidad de involucrarse.

Realizamos entrevistas personales con los interesados, intentando en todo momento hacerlos sentirse parte de esta primera experiencia en el país, de educación a distancia a través de videoconferencia interactiva.

\section{TECNOLOGÍA EMPLEADA}

Se empleó un equipamiento estándar PICTURETEL para la realización de videoconferencia interactiva entre dos sitios remotos. Contamos con soporte de un operador del sistema y un técnico en manejo de cámara en cada sitio (emisor y receptor). Empleamos líneas de comunicación dedicadas tipo Dataexpress, con un ancho de banda de $128 \mathrm{Kbps}$. Dispusimos de un micrófono tipo "solapero" para el docente y de un micrófono ambiental de alta fidelidad en el sitio remoto. La proyección remota se efectuó sobre un televisor de 33", amplificando el audio con un equipo estándar con dos parlantes mono.

Se dispuso de una cámara de documentos para el docente y se utilizó un equipo videorreproductor para ciertos ejercicios prácticos.

\section{Metodolocía del CuRSO}

Se intentó recrear un aula presencial. Se contó con una coordinación local que actuó como facilitadora animadora del grupo remoto, siendo por momentos una pieza fundamental en la organización de trabajos en grupo. Los docentes sustituyeron el pizarrón por hojas tipo carta, proyectadas por la cámara de documentos. La incorporación de un técnico en manejo de cámaras facilitó enormemente la identificación del alumnado por parte de los docentes, pudiendo visualizarse en primeros planos los diálogos docente-alumno. A pesar de la existencia de un retardo de fracción de segundo entre la emisión y la recepción - propia de esta tecnología-, se desarrollaron interacciones fluidas y sin dificultades.

Se entregó a cada participante el mismo material del programa dictado en forma presencial. Los docentes fomentaron el trabajo en grupo, dirigiendo en forma remota la actividad con la ayuda de la coordinación local. El apoyo de clases presenciales fue un elemento de importancia, pues permitió una aproximación más estrecha y el descubrimiento de algunos aspectos que dos dimensiones impedían apreciar. 


\section{DESARROLLO DE LOS SEMINARIOS}

A través de observaciones participantes intentamos recolectar datos sobre esta experiencia.

\section{EL CLIMA}

Sin duda alguna, el clima inicial era de extrema expectativa y de inquietud, dado que ésta era la primera experiencia para todos: docentes, alumnos, coordinadores y técnicos. Uno de los participantes manifestó: "No sé cómo será estar en un cohete a la Luna, pero pienso que esto fue lo más parecido". En las siguientes clases el grupo se fue distendiendo, fundamentalmente porque se percibía que la experiencia funcionaba y que, con algunas adaptaciones, era posible olvidarse del efec to distancia y sentirse compenetrado con la clase. Observamos que los participantes se vincularon rápidamente entre sí, de modo similar a esa unión que se produce cuando un grupo humano tiende a estrecharse ante lo desconocido para fortalecerse y sentir seguridad.

\section{LAS INTERACCIONES DIDÁCTICAS}

La interacción voluntaria alumno-docente es de inferior frecuencia que la de una actividad presencial, tanto en la cantidad de alumnos que participan como en las intervenciones efectuadas, pero las interacciones a demanda fueron superiores a las presenciales.

\section{IMPRESIONES DE LOS PARTICIPANTES}

En este aspecto nos aproximamos tanto cualitativa como cuantitativamente. Nos interesó conocer la razón principal por la cual se inscribieron en el programa. Obtuvimos que: $6(20 \%)$ lo hicieron buscando un crecimiento profesional, 12 ( 40\%) para desarrollar su formación y los restantes 12 $(40 \%)$ como complemento de su actividad laboral. En los comentarios emitidos en las clases y fuera de ellas, manifestaron un alto grado de satisfacción con esta experiencia. Tomaron conciencia respec to a la trascendencia de esta actividad para el futuro educativo de los ciudadanos del interior.

\section{REFLEXIONES FINALES}

Esta ha sido la primera experiencia de educación a distancia vía videoconferencia en el país. Su implementación y desarrollo ha generado fortalezas y debilidades. No es nuestra intención ahora destacar los aspectos positivos, que de alguna manera ya fueron esbozados en el informe; sí, nos gustaría señalar algunos puntos que habría que considerar especialmente en las próximas acciones:

* reflexionar sobre la didáctica en videoconferencia (si bien puede tener elementos en común con la clase presencial, se hace necesario desarrollar propuestas diferentes de transposición didáctica).

* generar estrategias metodológicas que favorezcan interacciones didácticas más espontáneas.

* investigar sobre las concepciones de enseñanza y de aprendizaje de docentes y alumnos con referencia a esta tecnología.

Bibliográfía

GROSZ,R. (1996) Distance Learning: Prospects \& Case Studies Bringing together people, process and technology. Londres: ORT International.

HILTZ,S. (1995) The Virtual Classroom: Learning without limits via computer networks. Norwood, New J ersey: Ablex Publishing.

INDIANA UNIVERSITY (1996) Distance Learning: A guide to System Planning and Implementation. Indianapolis: Indiana University.

KNIGHT,P. (1995) Education for all Through Electronic Distance Education. Washington: World Bank.

http://www.worldbank.org/html/emc/documents/ede2.html

STORCK,J \& SPROULL,L. (1995) Through a Glass Darkly - What Do People Learn in Videoconferences. Human Communication Research, Vol. 22, No. 2, December 1995, 197-219. Boston: Boston University.

UNIVERSITY OF WISCONSIN (1996) The Essential Compressed Video Guide- 7 Keys to Success. Instructional Communication Systems. Milwaukee, Wisconsin: University of Wisconsin-Extension. 